\title{
An early clinical trial of Salirasib, an oral RAS inhibitor, in Japanese patients with relapsed/refractory solid tumors
}

\author{
Junji Furuse ${ }^{1} \cdot$ Takayasu Kurata $^{2} \cdot$ Naohiro Okano $^{1} \cdot$ Yasuhito Fujisaka $^{2} \cdot$ Daisuke Naruge $^{1} \cdot$ Toshio Shimizu $^{2}$. \\ Hiroshi Kitamura ${ }^{1} \cdot$ Tsutomu Iwasa $^{2} \cdot$ Fumio Nagashima ${ }^{1} \cdot$ Kazuhiko Nakagawa $^{2}$
}

Received: 6 February 2018 / Accepted: 4 June 2018 / Published online: 10 July 2018

(c) The Author(s) 2018

\begin{abstract}
Purpose Patients with $R A S$-positive tumors respond poorly to chemotherapies and have a few treatment options. Salirasib is an oral RAS inhibitor that competitively blocks the membrane association of RAS proteins. The aim of this phase I multiple-ascending-dose clinical trial was to investigate the safety and pharmacokinetics of Salirasib in Japanese patients with relapsed/refractory solid tumors and to explore its efficacy.

Methods Salirasib was started at a dose of 100-mg twice-daily and escalated to a maximum of 1000-mg twice-daily from days 1 to 21 of a 28-day regimen. The pharmacokinetics was evaluated on days 1 and 21. Dose-limiting toxicity (DLT) and adverse events (AEs) were monitored throughout the trial. Patients with stable disease or better repeated the dosing regimen. Results A total of 21 patients received Salirasib. Among 14 patients tested, 4 had $K R A S$ mutations. $C_{\max }$ and AUC $\mathrm{Anf}_{\text {were }}$ maximal at $800 \mathrm{mg}$. No maximum tolerable dose was discerned, as no DLT was observed in any dosing group. The most frequently observed AEs were gastrointestinal disturbances, including diarrhea, abdominal pain, and nausea. No AEs led to discontinuation. All patients completed the first regimen and 11 patients repeated the regimen (median: 2 cycles; range: 1-13). Patients with KRAS mutations showed median progression-free survival of 227 days (range: 79-373).

Conclusion Salirasib was safe and well tolerated in Japanese patients, and 800-mg twice-daily is recommended for phase II trials. Although the number of participants with KRAS mutations was limited, the remarkably long progression-free period warrants further investigation.
\end{abstract}

Clinical trial registration JAPIC Clinical Trials Information; JapicCTI-121751.

Keywords KRAS mutation · Salirasib $\cdot S$-trans $\cdot$ Trans-farnesylthiosalicylic acid $\cdot$ Phase I clinical trial $\cdot$ Relapsed/refractory solid tumors

Electronic supplementary material The online version of this article (https://doi.org/10.1007/s00280-018-3618-4) contains supplementary material, which is available to authorized users.

Junji Furuse

jfuruse@ks.kyorin-u.ac.jp

1 Department of Medical Oncology, Kyorin University School of Medicine, 6-20-2 Shinkawa, Mitaka, Tokyo 181-8611, Japan

2 Department of Medical Oncology, Kindai University Faculty of Medicine, 377-2 Ohno-Higashi, Osaka-Sayama, Osaka 589-8511, Japan

\section{Introduction}

Cancer is the leading cause of death in developed countries. Single or combination of chemotherapy, surgical resection, and radiation therapy is selected according to cancer type. Recent advances in cancer research and molecularly targeted drugs offer better chemotherapy options in various cancers. The RAS pathway is one of the most important pathways and has been the subject of molecularly targeted drugs [1].

RAS (three isoforms: KRAS, HRAS, and NRAS) is a key downstream effector of the epidermal growth factor (EGF) signaling pathway, regulating physiological cell proliferation, differentiation, and apoptosis [1]. The prevalence of $R A S$ mutations is high in human cancers, being found in one-third of all cancers, $90 \%$ of pancreatic cancers, and $50 \%$ of colon cancers [1, 2]. Among the isoforms, KRAS is most 
commonly mutated [2]. In particular, because of the absence of symptoms, pancreatic cancer is often not found until advanced stage at which surgical resection may be not possible, resulting in a poor prognosis. Therefore, chemotherapy options to treat patients with RAS mutations are awaited.

Post-translationally farnesylated activated RAS binds to the plasma membrane and exerts a downstream signaling [3]. Mutated RAS is constitutively active without upstream EGF signaling, resulting in cancer-related uncontrolled RAS activities [1]. Several molecular drugs targeting EGF-RAS pathway have been developed, but their efficacy is not yet satisfactory in patients with $R A S$ mutations $[4,5]$.

Salirasib is an S-trans, trans-farnesylthiosalicylic acid and a novel oral RAS inhibitor [6-8]. Salirasib mimics c-terminal farnesyl cysteine, common to all RAS isoforms, and competes with farnesylated RAS for putative-binding sites on the plasma membrane, leading to degradation of active cytoplasmic RAS $[9,10]$. This mechanism of action may enable treatment of patients with $R A S$ mutations who do not respond to the standard chemotherapies. The previous phase I/II trials in the USA (CCA-FTS-101A/B, 102-105, 201) showed good tolerability, but the efficacy in $R A S$-mutated patients was not conclusive $[11,12]$. The present trial was a phase I trial to investigate the safety, tolerability, and pharmacokinetics of Salirasib in Japanese patients with relapsed/ refractory solid tumors. The efficacy of Salirasib was also evaluated in an exploratory analysis.

\section{Materials and methods}

\section{Patients and inclusion criteria}

This trial was approved by the ethics committees of our institutions and was conducted in accordance with Declaration of Helsinki principles. Written informed consent was obtained from all participants.

Patients were male or female Japanese cancer patients aged $\geq 20$ years at the time of obtaining written informed consent, who had relapsed/refractory solid tumors confirmed by histopathological examination, did not respond to standard therapies, and had expected survival of $\geq 3$ months. Key inclusion criteria were creatinine $\leq 1.5$ times upper limit of normal range (ULN); total bilirubin $\leq 2.0 \mathrm{mg}$ / $\mathrm{dL}$; aspartate aminotransferase (glutamate oxaloacetate transaminase) (AST [GOT]) and alanine aminotransferase (glutamate pyruvate transaminase) (ALT $[$ GPT]) $\leq 3$ times ULN; hemoglobin $\geq 9.0 \mathrm{~g} / \mathrm{dL}$; platelets $\geq 100 \times 10^{9}$ cells $/ \mathrm{L}$; neutrophils $\geq 1.5 \times 10^{9}$ cells/L. Patients with the following conditions were excluded: uncontrolled or severe concurrent medical conditions, including symptomatic primary/metastatic tumors in brain and meninges, renal/hepatic failures, and uncontrolled diabetes; complication of symptomatic ulceration or gastrointestinal conditions potentially interfering with oral administration and absorption; known infection with human immunodeficiency virus, hepatitis B, or hepatitis $\mathrm{C}$; any chemotherapy and/or radiotherapy within 28 days of test drug administration.

Patients voluntarily participating in our RAS mutation study provided additional written informed consent. Formalin-fixed paraffin-embedded tumor samples from 14 patients were sectioned and stained with hematoxylin-eosin. Tumor regions were selected by pathologists at Kyorin University or Kinki University and DNA was extracted using the QIAamp DNA Micro kit (Qiagen, Hilden, Germany). Mutations in KRAS codons 12 and 13 were examined using a kit based on a Luminex assay (MEBGEN KRASMutation Detection kit, MBL, Nagoya, Japan).

\section{Study design}

This trial was a multiple-ascending dose trial in 28-day cycles. The doses used were 100, 200, 400, 600, 800, and $1000 \mathrm{mg}$. The initial dose $(100 \mathrm{mg})$ was determined in accordance with the International Conference on Harmonisation of Technical Requirements for Registration of Pharmaceuticals for Human Use-S9 guideline [13]. Salirasib was orally administered twice-daily after meals from days 1 to 21 , followed by a 7-day pause. Patients received only the morning dose on day 1 for pharmacokinetics evaluation. Dose-limiting toxicity (DLT) was monitored throughout the 28-day regimen, with DLT defined as any of the following adverse events (AEs) for which a causal relationship with Salirasib was not ruled out: persistent grade 4 neutropenia for $>7$ days; grade $\geq 3$ febrile neutropenia; grade 4 thrombocytopenia or grade 3 thrombocytopenia requiring transfusion; nausea, vomiting, or diarrhea of grade $\geq 3$ despite optimal treatment; grade $\geq 3$ non-hematological toxicity leading to discontinuation of treatment. Grades were determined according to the National Cancer Institute Common Terminology Criteria for Adverse Events (NCI-CTCAE v.4.0).

Treatment was immediately terminated at the patient's request when DLT occurred; the study physician decided that continuation was inappropriate because of AEs; or if the tumor was classified as progressive disease (PD) according to the Response Evaluation Criteria in Solid Tumor (RECIST) Guideline [14]. In cases of DLT, patients were allowed to continue the regimen with dose adjustments upon providing written agreement.

Patients were registered when up to three patients received $\geq 60 \%$ of planned treatment in the regimen before DLT was evaluated for dose escalation. If no DLT was observed in any patient, the dose was escalated to the next lowest level and new patients were registered until three patients received $\geq 60 \%$ of planned treatment in that dose group. If one patient showed DLT, patients were added to 
the group to give a final number of 6 patients with $\geq 60 \%$ of planned treatment, and it was confirmed that no other patient showed DLT before escalating to the next lowest dose. If $\geq 2$ patients showed DLT in a dose group, the dose was to be considered to exceed the maximum tolerable dose and the ongoing regimen was to be discontinued. According to the DLT and pharmacokinetics data obtained by a given time, the recommended dose was determined and additional three patients were added to the dosing group a posteriori.

At the end of the regimen, patients were allowed to repeat the same regimen if all of the following criteria were met: no DLT occurred; the tumor was not determined as PD; the study physicians agreed; and the patient provided written informed consent. For the repeated regimen, Salirasib was administered twice-daily from day 1 .

\section{Pharmacokinetics}

Salirasib concentrations were measured in plasma and urine for pharmacokinetics analysis. Blood samples were collected 10 times on day 1 (before drug administration, and 0.5-, 1-, 1.5-, 2-, 4-, 6-, 8-, 12-, and 24-h post-administration), once on days 4,7 , and 14 , and 9 times on day 21 (before morning dose, and $0.5,1,1.5,2,4,6,8$, and $12 \mathrm{~h}$ after morning dose but before evening dose). Urine samples were collected from patients who received 200,600, or $1000 \mathrm{mg}$ on day 1 (before drug administration, and 0-6-, 6-12-, 12-24-h postadministration). Plasma and urine concentrations of Salirasib were determined by liquid chromatography-tandem mass spectrometry performed by LSI Medience Corporation (Tokyo, Japan).

\section{Safety}

To evaluate the safety, vital signs (systolic and diastolic blood pressure, pulse rate, body temperature, and body weight), 12-lead electrocardiogram, clinical laboratory tests, chest X-ray, and performance status [Eastern Cooperative Oncology Group (ECOG)] were evaluated on predefined dates (Supplemental Table S1). Examined items in the clinical laboratory tests are listed in Supplemental Table S2.

AEs were graded in accordance with NCI-CTCAE v.4.0 and recorded. The study physicians determined whether the AEs were drug-related and recorded.

\section{Exploratory evaluation of efficacy}

Diagnostic imaging using computed tomography, magnetic resonance imaging (MRI), fluorodeoxyglucose-positron emission tomography (PET), and/or bone scintigraphy was performed depending on the tumors and clinical symptoms on day 22 of first and repeated regimens or at discontinuation.
Specific tumor markers (e.g., carcinoembryonic antigen for colorectal cancer and prostate-specific antigen for prostate cancer) were measured on day 22 of first and repeated regimens or at discontinuation.

Based on the information obtained, the efficacy was scored in accordance with the RECIST guideline.

\section{Results}

\section{Patients}

A total of 23 patients were enrolled in the trial, and 21 patients received Salirasib treatment. The detailed patient characteristics are summarized in Table 1 and Supplemental Table S3.

\section{Pharmacokinetics}

Pharmacokinetics was analyzed in terms of plasma concentrations. Changes in plasma Salirasib levels over $24 \mathrm{~h}$ on days 1 and 21 are displayed in Fig. 1a, b. Plasma Salirasib reached maximum plasma concentration $\left(C_{\max }\right)$ at median of $1.97-4.00 \mathrm{~h}$ and half-life $\left(t_{1 / 2}\right)$ at mean of 3.5-9.11-h postadministration on day 1 , and $C_{\max }$ at $2.10-4.05 \mathrm{~h}$ on day 21. There was no apparent difference in pharmacokinetic parameters after single administration (day 1) compared to multiple administrations (day 21) (Table 2).

Power model analyses revealed that $C_{\max }$ and area under the plasma concentration-time curve from time 0 to infinity $\left(\mathrm{AUC}_{\text {inf }}\right)$ increased proportionally until $400 \mathrm{mg}$ in dosedependent manners (Fig. 1c, d), and less than proportionally until $800 \mathrm{mg}$, with no difference between 800- and 1000-mg groups (Table 2).

Within $24 \mathrm{~h}$, Salirasib was not excreted in urine in any dosing group.

\section{Safety}

During the treatment, no DLT was observed and all patients completed the first regimen. Therefore, all dosing regimens (100-, 200-, 400-, 600-, 800-, and 1000-mg twice-daily) were administered with three patients in each group, and three additional patients were added a posteriori in the $800 \mathrm{mg}$ group.

In the first and repeated regimens, AEs were observed in all 21 patients, with drug-related AEs in all patients except two (one patient each in 100- and 1000-mg groups). Occurrences of AEs are summarized in Table 3.

Most frequent AEs observed were gastrointestinal disturbances, occurring in more than two-thirds of patients in every dosing group. Drug-related AEs observed in $\geq 3$ patients were diarrhea, abdominal pain, nausea, decreased 
Table 1 Patient demographics and baseline characteristics

\begin{tabular}{|c|c|}
\hline & Total \\
\hline Patients $(N)$ & 21 \\
\hline \multicolumn{2}{|l|}{$\mathrm{Sex}, N(\%)$} \\
\hline Male & $14(66.7)$ \\
\hline Female & $7(33.3)$ \\
\hline \multicolumn{2}{|l|}{ Age (years) } \\
\hline$<65, N(\%)$ & $11(52.4)$ \\
\hline$\geq 65, N(\%)$ & $10(47.6)$ \\
\hline Mean \pm SD & $62.5 \pm 10.6$ \\
\hline Median & 63.0 \\
\hline Range, 52-74 & $43-80$ \\
\hline \multicolumn{2}{|l|}{ ECOG performance status, $N(\%)$} \\
\hline 0 & $16(76.2)$ \\
\hline 1 & $5(23.8)$ \\
\hline 2 & $0(0.0)$ \\
\hline \multicolumn{2}{|l|}{ Tumor type, $N(\%)$} \\
\hline Lung & $0(0.0)$ \\
\hline Pancreas & $5(23.8)$ \\
\hline Colorectal & $7(33.3)$ \\
\hline Stomach & $0(0.0)$ \\
\hline Esophagus & $1(4.8)$ \\
\hline Biliary tract & $4(19.0)$ \\
\hline Liver & $0(0.0)$ \\
\hline Others & $4(19.0)$ \\
\hline \multicolumn{2}{|l|}{ Stage of cancer, $N(\%)$} \\
\hline IV & $9(42.9)$ \\
\hline IVB & $2(9.5)$ \\
\hline Refractory & $10(47.6)$ \\
\hline \multicolumn{2}{|c|}{ Histopathological classification, $N(\%)$} \\
\hline Small round cell tumor & $1(4.8)$ \\
\hline Invasive ductal carcinoma & $1(4.8)$ \\
\hline Adenocarcinoma & 15 (71.4) \\
\hline Clear cell carcinoma & $1(4.8)$ \\
\hline Squamous cell carcinoma & $1(4.8)$ \\
\hline Acral lentiginous melanoma & $1(4.8)$ \\
\hline Unknown & $1(4.8)$ \\
\hline \multicolumn{2}{|c|}{ TNM staging (T) at study onset, $N(\%)$} \\
\hline T0 & 15 (71.4) \\
\hline $\mathrm{T} 3$ & $3(14.3)$ \\
\hline $\mathrm{T} 4$ & $3(14.3)$ \\
\hline \multicolumn{2}{|c|}{ TNM staging (N) at study onset, $N(\%)$} \\
\hline No & $11(52.4)$ \\
\hline N1 & $6(28.6)$ \\
\hline $\mathrm{N} 2$ & $1(4.8)$ \\
\hline $\mathrm{N} 2 \mathrm{~b}$ & $2(9.5)$ \\
\hline N3 & $1(4.8)$ \\
\hline \multicolumn{2}{|c|}{ TNM staging (M) at study onset, $N(\%)$} \\
\hline M0 & $1(4.8)$ \\
\hline M1 & 15 (71.4) \\
\hline M1b & $4(19.0)$ \\
\hline M1c & $1(4.8)$ \\
\hline
\end{tabular}

Table 1 (continued)

\begin{tabular}{|c|c|}
\hline & Total \\
\hline \multicolumn{2}{|l|}{ Treatment history: surgery ${ }^{\mathrm{a}}, N(\%)$} \\
\hline 0 & $5(23.8)$ \\
\hline$\geq 1$ & $16(76.2)$ \\
\hline Complete resection $^{\mathrm{a}}$ & $10(47.6)$ \\
\hline Residual tumor present ${ }^{\mathrm{a}}$ & $7(33.3)$ \\
\hline Unknown $^{\mathrm{a}}$ & $3(14.3)$ \\
\hline \multicolumn{2}{|l|}{ Treatment history: radiotherapy, $N(\%)$} \\
\hline 0 & $18(85.7)$ \\
\hline$\geq 1$ & $3(14.3)$ \\
\hline \multicolumn{2}{|l|}{ Prior systemic regimens, $N(\%)$} \\
\hline 0 & $0(0.0)$ \\
\hline 1 & $3(14.3)$ \\
\hline 2 & $6(28.6)$ \\
\hline 3 & $3(14.3)$ \\
\hline 4 & $3(14.3)$ \\
\hline 5 & $2(9.5)$ \\
\hline 6 & $4(19.0)$ \\
\hline$K R A S$ mutations determined, $N(\%)$ & $4(19.0)$ \\
\hline
\end{tabular}

ECOG Eastern Cooperative Oncology Group

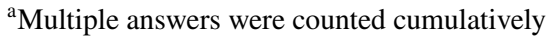

appetite, and vomiting (Table 3). AEs of grade $\geq 3$ were not observed in the first or repeated regimens in the 600$\mathrm{mg}$ group, but occasionally in all other dosing groups (Table 3). One serious AE (ascites) was found during the first regimen in the 100-mg group, but was not considered test drug-related. Otherwise, no serious AEs were observed in any dose group, and no AEs led to the early discontinuation of the regimen. No patients died during the treatment period.

\section{Exploratory evaluation of efficacy}

An exploratory efficacy evaluation of Salirasib was carried out. Response rates are listed in Table 4. Neither complete response (CR) nor partial response (PR) was found during the trial. Best response rates observed were stable disease (SD) $(0 / 3,2 / 3,1 / 3,2 / 3,1 / 6$, and $1 / 3$ patients in 100 , $200,400,600,800$, and $1000 \mathrm{mg}$ groups, respectively). All patients completed the first regimen and 11 patients repeated the regimen (Fig. 1e). Median overall total number of repeated cycles was 2 (range: 1-13) and median overall progression-free survival was 53 days (range: 16-373) (Table 4).

All four patients with KRAS mutations repeated the regimen (median: 8 cycles; range: 3-13) (Fig. 1e). Median progression-free survival in patients with KRAS mutations was 227 days (range: 79-373). 

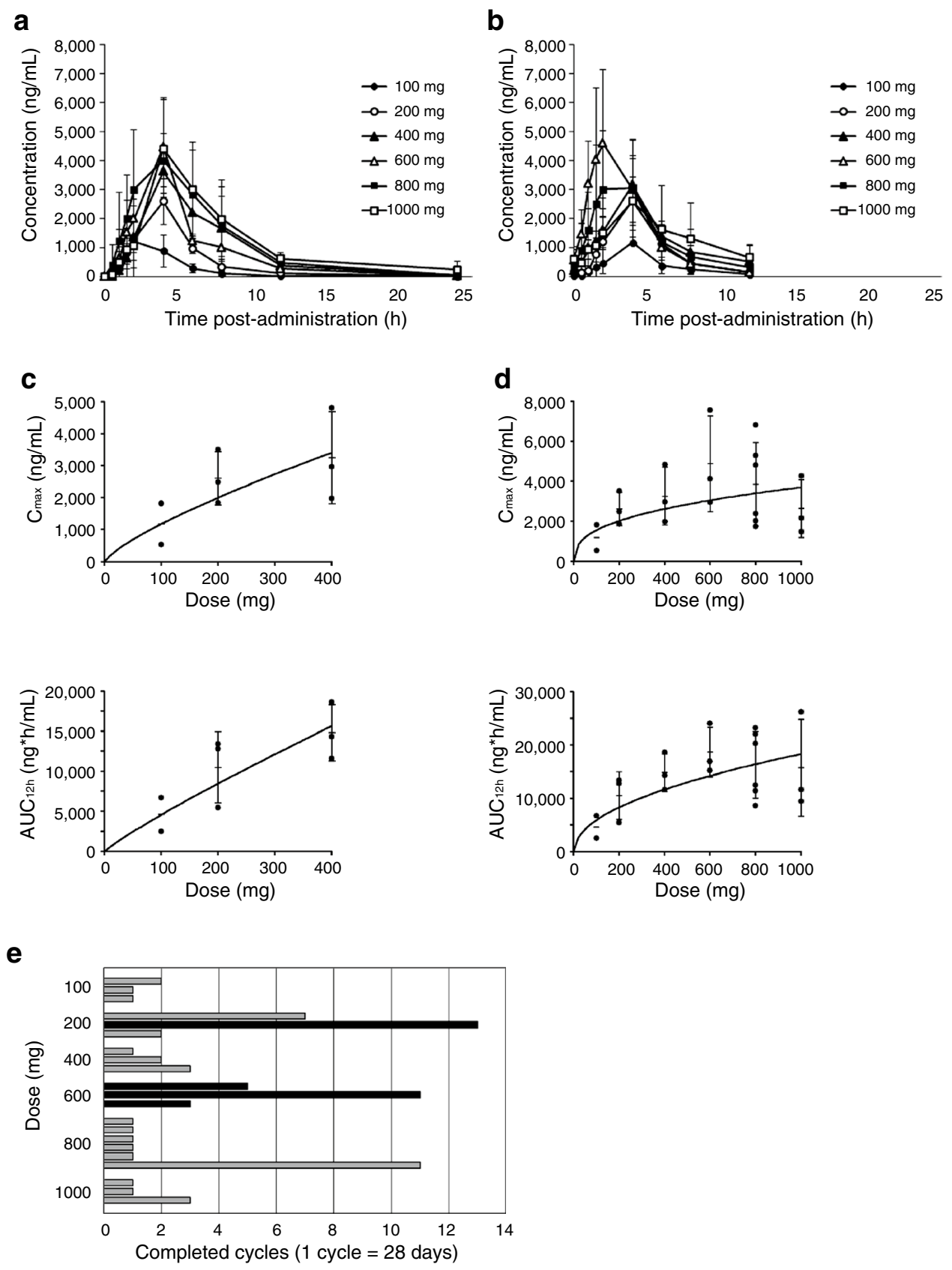

Fig. 1 a Changes in plasma concentrations of Salirasib over $24 \mathrm{~h}$ after single administration (day 1 of the first cycle). At median of 1.97-4.00-h post-administration, plasma Salirasib levels reached mean $C_{\max }$ of $1340-4990 \mathrm{ng} / \mathrm{mlL}$. b Changes in plasma concentration of Salirasib over $24 \mathrm{~h}$ after multiple administrations (day 21 of the first cycle). At median of 2.10-4.05-h post-administration, plasma Salirasib levels reached mean $C_{\max }$ of $1180-4870 \mathrm{ng} / \mathrm{mL}$. There were no apparent differences between pharmacokinetic parameters after single compared to multiple administrations. $\mathbf{c}$ Power model analyses for $C_{\max }$ (top) and $\mathrm{AUC}_{12 \mathrm{~h}}$ (bottom) for $0-400-\mathrm{mg}$ dosing on day 21 of the first cycle. $\mathrm{Up}$ to $400 \mathrm{mg}, C_{\max }$ and $\mathrm{AUC}_{12 \mathrm{~h}}$ increased propor- tionally and in dose-dependent manners. $\mathbf{d}$ Power model analyses for $C_{\max }$ (top) and $\mathrm{AUC}_{12 \mathrm{~h}}$ (bottom) for 0-1000-mg dosing on day 21 of the first cycle. Plasma concentration of Salirasib did not proportionally increase after administration of $600 \mathrm{mg}$ and higher doses. e Numbers of cycles completed. Patients who received $\geq 60 \%$ of planned medication before discontinuation were considered to have completed the regimen. All 21 patients completed at least the first regimen. Note the successful repeated regimens over a long period without progressive disease in patients with known KRAS mutations (black bars). $\mathrm{AUC}_{12 \mathrm{~h}}$ area under the plasma concentration-time curve from time 0 to $12 \mathrm{~h}, C_{\max }$ maximum plasma concentration 
Table 2 Pharmacokinetic parameters of Salirasib in the first regimen (days 1 and 21)

\begin{tabular}{|c|c|c|c|c|c|c|}
\hline & $100 \mathrm{mg}$ & $200 \mathrm{mg}$ & $400 \mathrm{mg}$ & $600 \mathrm{mg}$ & $800 \mathrm{mg}$ & $1000 \mathrm{mg}$ \\
\hline \multicolumn{7}{|c|}{ Pharmacokinetic parameters on day 1} \\
\hline Patients $(N)$ & 3 & 3 & 3 & 3 & 6 & 3 \\
\hline$C_{\max }(\mathrm{ng} / \mathrm{mL})$, mean $\pm \mathrm{SD}$ & $1340 \pm 473$ & $2830 \pm 822$ & $3630 \pm 876$ & $4500 \pm 1580$ & $4790 \pm 1100$ & $4990 \pm 1210$ \\
\hline \multicolumn{7}{|l|}{$t_{\max }(\mathrm{h})$} \\
\hline Median & 1.97 & 3.98 & 4.00 & 3.98 & 3.99 & 3.97 \\
\hline Range & $1.52-3.88$ & $2.13-4.00$ & $4.00-4.03$ & $1.42-4.00$ & $2.02-5.93$ & $3.97-6.37$ \\
\hline $\mathrm{AUC}_{\text {inf }}(\mathrm{ng} \mathrm{h} / \mathrm{mL})$, mean $\pm \mathrm{SD}$ & $4970 \pm 1600$ & $11,400 \pm 3580$ & $20,300 \pm 3710$ & $18,500 \pm 3060$ & $26,600 \pm 4200$ & $26,900^{\mathrm{a}}$ \\
\hline $\mathrm{AUC}_{12 \mathrm{~h}}(\mathrm{ng} \mathrm{h} / \mathrm{mL})$, mean $\pm \mathrm{SD}$ & $4700 \pm 1490$ & $10,400 \pm 3180$ & $18,000 \pm 4060$ & $16,900 \pm 2880$ & $23,800 \pm 3010$ & $22,400 \pm 2890$ \\
\hline$t_{1 / 2}(\mathrm{~h})$, mean $\pm \mathrm{SD}$ & $3.81 \pm 0.25$ & $4.16 \pm 1.13$ & $4.00 \pm 1.88$ & $3.50 \pm 0.39$ & $3.67 \pm 0.81$ & $9.11 \pm 9.79$ \\
\hline $\mathrm{CL} / \mathrm{F}(\mathrm{L} / \mathrm{h})$, mean $\pm \mathrm{SD}$ & $21.6 \pm 6.80$ & $19.1 \pm 7.35$ & $20.1 \pm 3.83$ & $33.0 \pm 5.25$ & $30.7 \pm 4.55$ & $38.3^{\mathrm{a}}$ \\
\hline \multicolumn{7}{|c|}{ Pharmacokinetic parameters on day 21} \\
\hline Patients $(N)$ & 2 & 3 & 3 & 3 & 6 & 3 \\
\hline$C_{\max }(\mathrm{ng} / \mathrm{mL})$, mean $\pm \mathrm{SD}$ & $1180^{\mathrm{a} 1}$ & $2610 \pm 837$ & $3250 \pm 1440$ & $4870 \pm 2390$ & $3840 \pm 2090$ & $2630 \pm 1450$ \\
\hline \multicolumn{7}{|l|}{$t_{\max }(\mathrm{h})$} \\
\hline Median & 4.05 & 3.93 & 3.97 & 2.10 & 2.98 & 3.95 \\
\hline Range & $4.05-4.05$ & $3.92-4.00$ & $3.97-6.00$ & $2.00-4.00$ & $1.42-5.98$ & $2.00-3.97$ \\
\hline $\mathrm{AUC}_{12 \mathrm{~h}}(\mathrm{ng} \mathrm{h} / \mathrm{mL})$, mean $\pm \mathrm{SD}$ & $4610^{\mathrm{a}}$ & $10,500 \pm 4450$ & $14,800 \pm 3520$ & $18,700 \pm 4710$ & $16,300 \pm 6240$ & $15,700 \pm 9100$ \\
\hline
\end{tabular}

$A U C_{12 h}$ area under the plasma concentration-time curve from time $0-12 \mathrm{~h}, A U C_{i n f}$ area under the plasma concentration-time curve from time 0 to infinity, $\mathrm{CL} / \mathrm{F}$ apparent clearance, $C_{\max }$ maximum plasma concentration, $t_{1 / 2}$ half-life, $t_{\max }$ time of maximum plasma concentration

${ }^{\mathrm{a}} \mathrm{SD}$ was not calculated because of missing data

\section{Discussion}

This phase I clinical trial investigated the safety and tolerability of Salirasib, a novel oral RAS inhibitor, for the first time in Japanese patients.

Throughout the trial, including first and repeated regimens, frequency and severity of AEs and drug-related AEs did not apparently differ in any dose groups. Most frequently observed drug-related AEs were gastrointestinal toxicities, such as diarrhea, abdominal pain, and nausea, consistent with the previous phase I/II trials carried out in US patients $[11,12,15]$. In all dose groups, no DLT was observed and no patients discontinued the trial for AEs. Therefore, Salirasib is considered to be safe and tolerable up to $1000 \mathrm{mg}$ in Japanese patients. In a phase I trial in the US patients [15], no DLT was observed up to $800 \mathrm{mg}$, although all patients on 800-mg regimen experienced drug-related AEs, consistent with our trial. Pharmacokinetic analyses in our study showed that $\mathrm{C}_{\max }$ and AUC increased with escalating doses of up to $800 \mathrm{mg}$. These results together with the safety profile indicate that $800 \mathrm{mg}$ twice-daily is the recommended dose for Japanese patients. The tolerability was demonstrated across all types of cancers investigated in the study. Therefore, no cancer types have to be excluded from future trials in terms of safety.

In a previous phase II trial in patients with KRAS mutations, no patients achieved PR [11]. Consistent with the study, no patients showed CR or PR with Salirasib in our trial. Although the efficacy data are not conclusive due to the small number of patients included, it is worth noting the long period of SD and number of repeated treatments in the present trial. Therefore, further study to investigate the efficacy of Salirasib is encouraged.

Patients with KRAS-mutated tumors respond to chemotherapies poorly. EGF receptor inhibitors (e.g., panitumumab) show a little efficacy in patients with KRAS mutations [4, 16, 17], owing to EGF receptor-independent constitutive activities of RAS mutants. Molecular drugs targeting prenylation of RAS, such as farnesyl transferase inhibitors (e.g., tipifarnib), also showed a little activity in clinical trials [18-20], partially because membrane association of KRAS and NRAS mutants can still take place via alternative modification pathway through geranylgeranyltransferase-I, even though farnesylation of RAS is successfully inhibited [21, 22]. In turn, although no patients achieved PR, all patients with KRAS mutations in this study repeated the Salirasib regimen before they were discontinued due to PD, demonstrating its potential to control disease activity. To our knowledge, this is the first indication that Salirasib may be effective treatment for patients with KRAS mutations who are non-responsive to other chemotherapies.

In future trials, it would also be of interest to compare the efficacy in cohorts stratified according to the presence of $R A S$ mutations. Efficacy analyses could be performed in patients with pancreatic or colorectal cancers, because $R A S$ mutations are more frequent in those types of cancers. 
Table 3 Summary of occurrences of adverse events (AEs) in the first and repeated regimens

\begin{tabular}{|c|c|c|c|c|c|c|c|}
\hline & $100 \mathrm{mg}$ & $200 \mathrm{mg}$ & $400 \mathrm{mg}$ & $600 \mathrm{mg}$ & $800 \mathrm{mg}$ & $1000 \mathrm{mg}$ & Total \\
\hline Patients $(N)$ & 3 & 3 & 3 & 3 & 6 & 3 & 21 \\
\hline All AEs, $N(\%)$ & $3(100)$ & $3(100)$ & $3(100)$ & $3(100)$ & $6(100)$ & $3(100)$ & $21(100)$ \\
\hline Patients with AEs of grade $\geq 3, N(\%)$ & $2(66.7)$ & $1(33.3)$ & $2(66.7)$ & $0(0.0)$ & $2(33.3)$ & $2(66.7)$ & $9(42.9)$ \\
\hline Serious AEs, $N(\%)$ & $1(33.3)$ & $0(0.0)$ & $0(0.0)$ & $0(0.0)$ & $0(0.0)$ & $0(0.0)$ & $1(4.8)$ \\
\hline Discontinuation because of AEs, $N(\%)$ & $0(0.0)$ & $0(0.0)$ & $0(0.0)$ & $0(0.0)$ & $0(0.0)$ & $0(0.0)$ & $0(0.0)$ \\
\hline All drug-related AEs, $N(\%)$ & $2(66.7)$ & $3(100)$ & $3(100)$ & $3(100)$ & $6(100)$ & $2(66.7)$ & $19(90.5)$ \\
\hline Patients with drug-related AEs of grade $\geq 3, N(\%)$ & $0(0.0)$ & $0(0.0)$ & $1(33.3)$ & $0(0.0)$ & $1(16.7)$ & $2(66.7)$ & $4(19.0)$ \\
\hline Serious drug-related AEs, $N(\%)$ & $0(0.0)$ & $0(0.0)$ & $0(0.0)$ & $0(0.0)$ & $0(0.0)$ & $0(0.0)$ & $0(0.0)$ \\
\hline Discontinuation because of drug-related AEs, $N(\%)$ & $0(0.0)$ & $0(0.0)$ & $0(0.0)$ & $0(0.0)$ & $0(0.0)$ & $0(0.0)$ & $0(0.0)$ \\
\hline Dose-limiting toxicity (DLT), $N(\%)$ & $0(0.0)$ & $0(0.0)$ & $0(0.0)$ & $0(0.0)$ & $0(0.0)$ & $0(0.0)$ & $0(0.0)$ \\
\hline Death, $N(\%)$ & $0(0.0)$ & $0(0.0)$ & $0(0.0)$ & $0(0.0)$ & $0(0.0)$ & $0(0.0)$ & $0(0.0)$ \\
\hline \multicolumn{8}{|l|}{ AEs observed in $\geq 3$ patients, $N(\%)$} \\
\hline Diarrhea & $2(66.7)$ & $2(66.7)$ & $3(100)$ & $3(100)$ & $6(100)$ & $2(66.7)$ & $18(85.7)$ \\
\hline Abdominal pain & $1(33.3)$ & $0(0.0)$ & $3(100)$ & $0(0.0)$ & $1(16.7)$ & $1(33.3)$ & $6(28.6)$ \\
\hline Nausea & $1(33.3)$ & $0(0.0)$ & $2(66.7)$ & $2(66.7)$ & $1(16.7)$ & $0(0.0)$ & $6(28.6)$ \\
\hline Decreased appetite & $1(33.3)$ & $0(0.0)$ & $1(33.3)$ & $1(33.3)$ & $4(66.7)$ & $2(66.7)$ & $9(42.9)$ \\
\hline Vomiting & $0(0.0)$ & $0(0.0)$ & $1(33.3)$ & $2(66.7)$ & $1(16.7)$ & $0(0.0)$ & $4(19.0)$ \\
\hline \multicolumn{8}{|l|}{ AEs observed at grade $\geq 3, N(\%)$} \\
\hline Diarrhea & $0(0.0)$ & $0(0.0)$ & $0(0.0)$ & $0(0.0)$ & $1(16.7)$ & $1(33.3)$ & $2(9.5)$ \\
\hline Anemia & $1(33.3)$ & $0(0.0)$ & $0(0.0)$ & $0(0.0)$ & $0(0.0)$ & $1(33.3)$ & $2(9.5)$ \\
\hline Ascites & $1(33.3)$ & $0(0.0)$ & $0(0.0)$ & $0(0.0)$ & $0(0.0)$ & $0(0.0)$ & $1(4.8)$ \\
\hline Cholestatic jaundice & $0(0.0)$ & $1(33.3)$ & $0(0.0)$ & $0(0.0)$ & $0(0.0)$ & $0(0.0)$ & $1(4.8)$ \\
\hline Amylase increased & $0(0.0)$ & $0(0.0)$ & $1(33.3)$ & $0(0.0)$ & $0(0.0)$ & $0(0.0)$ & $1(4.8)$ \\
\hline Hyponatremia & $1(33.3)^{\mathrm{a}}$ & $0(0.0)$ & $1(33.3)$ & $0(0.0)$ & $0(0.0)$ & $0(0.0)$ & $2(9.5)$ \\
\hline Hypercalcemia & $0(0.0)$ & $0(0.0)$ & $1(33.3)$ & $0(0.0)$ & $0(0.0)$ & $0(0.0)$ & $1(4.8)$ \\
\hline Hypophosphatemia & $0(0.0)$ & $0(0.0)$ & $1(33.3)$ & $0(0.0)$ & $0(0.0)$ & $0(0.0)$ & $1(4.8)$ \\
\hline Bilirubin increased & $0(0.0)$ & $1(33.3)$ & $0(0.0)$ & $0(0.0)$ & $0(0.0)$ & $0(0.0)$ & $1(4.8)$ \\
\hline$\gamma$-GTP increased & $1(33.3)$ & $1(33.3)$ & $0(0.0)$ & $0(0.0)$ & $0(0.0)$ & $1(33.3)$ & $3(14.3)$ \\
\hline AST increased & $0(0.0)$ & $1(33.3)$ & $0(0.0)$ & $0(0.0)$ & $0(0.0)$ & $0(0.0)$ & $1(4.8)$ \\
\hline ALP increased & $0(0.0)$ & $1(33.3)$ & $0(0.0)$ & $0(0.0)$ & $1(16.7)$ & $1(33.3)$ & $3(14.3)$ \\
\hline Troponin $\mathrm{T}$ increased & $0(0.0)$ & $0(0.0)$ & $0(0.0)$ & $0(0.0)$ & $0(0.0)$ & $1(33.3)$ & $1(4.8)$ \\
\hline Hemoglobin decreased & $1(33.3)$ & $0(0.0)$ & $0(0.0)$ & $0(0.0)$ & $0(0.0)$ & $1(33.3)$ & $2(9.5)$ \\
\hline Lymphopenia & $1(33.3)^{\mathrm{a}}$ & $0(0.0)$ & $0(0.0)$ & $0(0.0)$ & $0(0.0)$ & $0(0.0)$ & $1(4.8)$ \\
\hline Decreased appetite & $1(33.3)$ & $0(0.0)$ & $0(0.0)$ & $0(0.0)$ & $0(0.0)$ & $0(0.0)$ & $1(4.8)$ \\
\hline Cancer pain & $1(33.3)$ & $0(0.0)$ & $0(0.0)$ & $0(0.0)$ & $0(0.0)$ & $0(0.0)$ & $1(4.8)$ \\
\hline
\end{tabular}

$A L P$ alkaline phosphatase, $A S T$ aspartate aminotransferase, $\gamma$-GTP gamma-glutamyl transpeptidase

${ }^{\mathrm{a}}$ Grade 4

Furthermore, in lung adenocarcinoma, it has been demonstrated that KRAS mutation induces the expression of programmed death ligand 1 (PD-L1) [23, 24]. Accordingly, combination therapy of Salirasib with an anti-PD-1 agent may enhance the anti-cancer efficacy.
Salirasib was well tolerated, and although our efficacy analyses were not conclusive, the results indicate that RAS inhibitors are a promising molecular approach, especially for patients with KRAS mutations who currently have no other effective therapy options. 
Table 4 Efficacy analyses assessed by physicians at the study sites

\begin{tabular}{|c|c|c|c|c|c|c|c|}
\hline & $100 \mathrm{mg}$ & $200 \mathrm{mg}$ & $400 \mathrm{mg}$ & $600 \mathrm{mg}$ & $800 \mathrm{mg}$ & $1000 \mathrm{mg}$ & Total \\
\hline Patients $(N)$ & 3 & 3 & 3 & 3 & 6 & 3 & 21 \\
\hline \multicolumn{8}{|l|}{ Response rate ${ }^{\mathrm{a}}, N(\%)$} \\
\hline Complete response (CR) & $0(0.0)$ & $0(0.0)$ & $0(0.0)$ & $0(0.0)$ & $0(0.0)$ & $0(0.0)$ & $0(0.0)$ \\
\hline Partial response (PR) & $0(0.0)$ & $0(0.0)$ & $0(0.0)$ & $0(0.0)$ & $0(0.0)$ & $0(0.0)$ & $0(0.0)$ \\
\hline Stable disease (SD) & $1(33.3)$ & $3(100.0)$ & $2(66.7)$ & $2(66.7)$ & $1(16.7)$ & $1(33.3)$ & $10(47.6)$ \\
\hline Progressive disease (PD) & $2(66.7)$ & $0(0.0)$ & $1(33.3)$ & $1(33.3)$ & $3(50.0)$ & $2(66.7)$ & $9(42.9)$ \\
\hline Objective response rate (ORR): $\mathrm{CR}+\mathrm{PR}$ & $0(0.0)$ & $0(0.0)$ & $0(0.0)$ & $0(0.0)$ & $0(0.0)$ & $0(0.0)$ & $0(0.0)$ \\
\hline Disease control rate (DCR): $\mathrm{CR}+\mathrm{PR}+\mathrm{SD}$ & $1(33.3)$ & $3(100.0)$ & $2(66.7)$ & $2(66.7)$ & $1(16.7)$ & $1(33.3)$ & $10(47.6)$ \\
\hline \multicolumn{8}{|l|}{ Number of cycles completed ${ }^{\mathrm{b}}$} \\
\hline Median & 1 & 7 & 2 & 5 & 1 & 1 & 2 \\
\hline Range & $1-2$ & $2-13$ & $1-3$ & $3-11$ & $1-11$ & $1-3$ & $1-13$ \\
\hline \multicolumn{8}{|l|}{ Progression-free survival ${ }^{\mathrm{c}}$ (days) } \\
\hline Median & 22 & 213 & 56 & 135 & 29 & 22 & 53 \\
\hline Range & $16-53$ & $57-373$ & $22-91$ & $79-319$ & $22-307$ & $22-91$ & $16-373$ \\
\hline
\end{tabular}

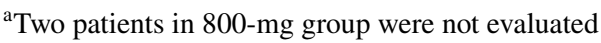

${ }^{\mathrm{b}}$ It was recorded as "completed" when patients underwent $\geq 60 \%$ of planned treatment in the ongoing regimen

${ }^{\mathrm{c}}$ For one patient in 800-mg group, days until withdrawal were counted, because of the early discontinuation but without PD

Acknowledgements The authors gratefully acknowledge the patients, their family members, nurses, and staff members who participated in this trial. The authors thank Miyuki Tauchi, Ph.D., and ASCA Corporation for providing professional help in writing the manuscript.

Funding This work was funded by Ono Pharmaceutical Co., Ltd.

\section{Compliance with ethical standards}

Conflict of interest Junji Furuse has received honoraria from Taiho Pharmaceutical, Chugai Pharmaceutical, Yakult, Kyowa Hakko Kirin, Eli Lilly Japan, Ono Pharmaceutical, Eisai, Bayer Pharmaceutical, Zeria Pharmaceutical, Fujifilm, Merck Serono, Novartis, J-Pharma, Otsuka Pharmaceutical, Boehringer Ingelheim, Takeda Pharmaceutical, Daiichi Sankyo, Astra Zeneca, Astellas Pharma, Mitsubishi Tanabe Pharma, Bristol-Myers Squibb, MSD, Meiji Seika Pharma, Ajinomoto Pharmaceuticals, Nippon Kayaku, Sumitomo Dainippon Pharma, Sawai, Sandoz, Mochida Pharma and Shionogi, and research funding from Taiho Pharmaceutical, Ono Pharmaceutical, Onco Therapy Science, Merck Serono, Zeria Pharmaceutical, Eli Lilly Japan, Takeda Pharmaceutical, Chugai Pharmaceutical, Bayer Pharmaceutical, Glaxo Smith Kline, Yakult, Sumitomo Dainippon Pharma, Daiichi Sankyo, Shionogi, Novartis, Torii Pharma, J-Pharma, Nippon Kayaku, BristolMyers Squibb, Janssen Pharmaceutical, Sanofi, Kyowa Hakko Kirin, Mochida Pharma, Astellas Pharma, Hisamitsu Pharmaceutical and Pfizer. Takayasu Kurata has received honoraria from Ono Pharmaceutical. Naohiro Okano and Daisuke Naruge have received research funding from Taiho Pharmaceutical, Ono Pharmaceutical, Onco Therapy Science, Merck Serono, Zeria Pharmaceutical, Eli Lilly Japan, Takeda Pharmaceutical, Chugai Pharmaceutical, Bayer Pharmaceutical, Glaxo Smith Kline, Yakult, Sumitomo Dainippon Pharma, Daiichi Sankyo, Shionogi, Novartis, Torii Pharma, J-Pharma, Nippon Kayaku, Bristol-Myers Squibb, Janssen Pharmaceutical, Sanofi, Kyowa Hakko Kirin, Mochida Pharma, Astellas Pharma, Hisamitsu Pharmaceutical and Pfizer. Fumio Nagashima has received honoraria from Taiho Pharmaceutical, Chugai Pharmaceutical, Kyowa Hakko Kirin, Merck Serono, Takeda Pharmaceutical, Daiichi Sankyo, Mitsubishi Tanabe
Pharma, Bristol-Myers Squibb, Nippon Kayaku and Sumitomo Dainippon Pharma, and research funding from Taiho Pharmaceutical, Ono Pharmaceutical, Onco Therapy Science, Merck Serono, Zeria Pharmaceutical, Eli Lilly Japan, Takeda Pharmaceutical, Chugai Pharmaceutical, Bayer Pharmaceutical, Glaxo Smith Kline, Yakult, Sumitomo Dainippon Pharma, Daiichi Sankyo, Shionogi, Novartis, Torii Pharma, J-Pharma, Nippon Kayaku, Bristol- Myers Squibb, Janssen Pharmaceutical, Sanofi, Kyowa Hakko Kirin, Mochida Pharma, Astellas Pharma, Hisamitsu Pharmaceutical and Pfizer. Kazuhiko Nakagawa has received honoraria from Astellas Pharma, AstraZeneca K.K., Chugai Pharmaceutical, Nippon Boehringer Ingelheim, Eli Lilly Japan K.K., Pfizer Japan and Novartis Pharma K.K., and research funding from Chugai Pharmaceutical, Astellas Pharma, MSD K.K., Ono Pharmaceutical, EPS Associates, Quintiles, Daiichi Sankyo, Japan Clinical Research Operations, Eisai, Kyowa Hakko Kirin, Pfizer Japan, Takeda Pharmaceutical, Nippon Boehringer Ingelheim, Bristol-Myers Squibb, and PPD-SNBL K.K.. The other authors declare no conflict of interest.

Ethical approval All procedures performed in studies involving human participants were in accordance with the ethical standards of the institutional and/or national research committee and with the 1964 Helsinki declaration and its later amendments or comparable ethical standards.

Informed consent Informed consent was obtained from all individual participants included in the study.

Open Access This article is distributed under the terms of the Creative Commons Attribution 4.0 International License (http://creativeco mmons.org/licenses/by/4.0/), which permits unrestricted use, distribution, and reproduction in any medium, provided you give appropriate credit to the original author(s) and the source, provide a link to the Creative Commons license, and indicate if changes were made. 


\section{References}

1. Roberts PJ, Der CJ (2007) Targeting the Raf-MEK-ERK mitogenactivated protein kinase cascade for the treatment of cancer. Oncogene 26:3291-3310

2. Bos JL (1989) ras oncogenes in human cancer: a review. Cancer Res 49:4682-4689

3. Casey PJ, Solski PA, Der CJ, Buss JE (1989) p21ras is modified by a farnesyl isoprenoid. Proc Natl Acad Sci USA 86:8323-8327

4. Douillard JY, Oliner KS, Siena S, Tabernero J, Burkes R, Barugel M, Humblet Y, Bodoky G, Cunningham D, Jassem J, Rivera F, Kocákova I, Ruff P, Błasińska-Morawiec M, Šmakal M, Canon JL, Rother M, Williams R, Rong A, Wiezorek J, Sidhu R, Patterson SD (2013) Panitumumab-FOLFOX4 treatment and RAS mutations in colorectal cancer. N Engl J Med 369:1023-1034

5. Poulin-Costello M, Azoulay L, Van Cutsem E, Peeters M, Siena S, Wolf M (2013) An analysis of the treatment effect of panitumumab on overall survival from a phase 3 , randomized, controlled, multicenter trial (20020408) in patients with chemotherapy refractory metastatic colorectal cancer. Target Oncol 8:127-136

6. Weisz B, Giehl K, Gana-Weisz M, Egozi Y, Ben-Baruch G, Marciano D, Gierschik P, Kloog Y (1999) A new functional Ras antagonist inhibits human pancreatic tumor growth in nude mice. Oncogene 18:2579-2588

7. Egozi Y, Weisz B, Gana-Weisz M, Ben-Baruch G, Kloog Y (1999) Growth inhibition of ras-dependent tumors in nude mice by a potent ras-dislodging antagonist. Int J Cancer 80:911-918

8. Laheru D, Shah P, Rajeshkumar NV, McAllister F, Taylor G, Goldsweig H, Le DT, Donehower R, Jimeno A, Linden S, Zhao M, Song D, Rudek MA, Hidalgo M (2012) Integrated preclinical and clinical development of $S$-trans, trans-Farnesylthiosalicylic Acid (FTS, Salirasib) in pancreatic cancer. Invest New Drugs 30:2391-2399

9. Marom M, Haklai R, Ben-Baruch G, Marciano D, Egozi Y, Kloog Y (1995) Selective inhibition of Ras-dependent cell growth by farnesylthiosalisylic acid. J Biol Chem 270:22263-22270

10. Haklai R, Weisz MG, Elad G, Paz A, Marciano D, Egozi Y, BenBaruch G, Kloog Y (1998) Dislodgment and accelerated degradation of Ras. Biochemistry 37:1306-1314

11. Riely GJ, Johnson ML, Medina C, Rizvi NA, Miller VA, Kris MG, Pietanza MC, Azzoli CG, Krug LM, Pao W, Ginsberg MS (2011) A phase II trial of salirasib in patients with lung adenocarcinomas with KRAS mutations. J Thorac Oncol 6:1435-1437

12. Badar T, Cortes JE, Ravandi F, O’Brien S, Verstovsek S, GarciaManero G, Kantarjian H, Borthakur G (2015) Phase I study of S-trans, trans-farnesylthiosalicylic acid (salirasib), a novel oral RAS inhibitor in patients with refractory hematologic malignancies. Clin Lymphoma Myeloma Leuk 15:433-438

13. International Conference on Harmonisation - safety guidance documents; S9 Nonclinical Evaluation for Anticancer Pharmaceuticals (2010) U.S. Department of Health and Human Services, Food and Drug Administration. https://www.fda.gov/downloads/ Drugs/Guidances/ucm085389.pdf. Accessed 30 Aug 2017

14. Eisenhauer EA, Therasse P, Bogaerts J, Schwartz LH, Sargent D, Ford R, Dancey J, Arbuck S, Gwyther S, Mooney M, Rubinstein L, Shankar L, Dodd L, Kaplan R, Lacombe D, Verweij J
(2009) New response evaluation criteria in solid tumours: revised RECIST guideline (version 1.1). Eur J Cancer 45:228-247

15. Tsimberidou AM, Rudek MA, Hong D, Ng CS, Blair J, Goldsweig H, Kurzrock R (2010) Phase 1 first-in-human clinical study of $S$-trans,trans-farnesylthiosalicylic acid (salirasib) in patients with solid tumors. Cancer Chemother Pharmacol 65:235-241

16. Amado RG, Wolf M, Peeters M, Van Cutsem E, Siena S, Freeman DJ, Juan T, Sikorski R, Suggs S, Radinsky R, Patterson SD, Chang DD (2008) Wild-type KRAS is required for panitumumab efficacy in patients with metastatic colorectal cancer. J Clin Oncol 26:1626-1634

17. Peeters M, Douillard JY, Van Cutsem E, Siena S, Zhang K, Williams R, Wiezorek J (2013) Mutant KRAS codon 12 and 13 alleles in patients with metastatic colorectal cancer: assessment as prognostic and predictive biomarkers of response to panitumumab. J Clin Oncol 31:759-765

18. Berndt N, Hamilton AD, Sebti SM (2011) Targeting protein prenylation for cancer therapy. Nat Rev Cancer 11:775-791

19. Van Cutsem E, van de Velde H, Karasek P, Oettle H, Vervenne WL, Szawlowski A, Schoffski P, Post S, Verslype C, Neumann H, Safran H, Humblet Y, Perez Ruixo J, Ma Y, Von Hoff D (2004) Phase III trial of gemcitabine plus tipifarnib compared with gemcitabine plus placebo in advanced pancreatic cancer. J Clin Oncol 22:1430-1438

20. Rao S, Cunningham D, de Gramont A, Scheithauer W, Smakal M, Humblet Y, Kourteva G, Iveson T, Andre T, Dostalova J, Illes A, Belly R, Perez-Ruixo JJ, Park YC, Palmer PA (2004) Phase III double-blind placebo-controlled study of farnesyl transferase inhibitor R115777 in patients with refractory advanced colorectal cancer. J Clin Oncol 22:3950-3957

21. Whyte DB, Kirschmeier P, Hockenberry TN, Nunez-Oliva I, James L, Catino JJ, Bishop WR, Pai JK (1997) K- and N-Ras are geranylgeranylated in cells treated with farnesyl protein transferase inhibitors. J Biol Chem 272:14459-14464

22. Lerner EC, Zhang TT, Knowles DB, Qian Y, Hamilton AD, Sebti SM (1997) Inhibition of the prenylation of K-Ras, but not H- or $\mathrm{N}$-Ras, is highly resistant to CAAX peptidomimetics and requires both a farnesyltransferase and a geranylgeranyltransferase I inhibitor in human tumor cell lines. Oncogene 15:1283-1288

23. Skoulidis F, Byers LA, Diao L, Papadimitrakopoulou VA, Tong P, Izzo J, Behrens C, Kadara H, Parra ER, Canales JR, Zhang J, Giri U, Gudikote J, Cortez MA, Yang C, Fan Y, Peyton M, Girard L, Coombes KR, Toniatti C, Heffernan TP, Choi M, Frampton GM, Miller V, Weinstein JN, Herbst RS, Wong KK, Zhang J, Sharma P, Mills GB, Hong WK, Minna JD, Allison JP, Futreal A, Wang J, Wistuba II, Heymach JV (2015) Co-occurring genomic alterations define major subsets of KRAS-mutant lung adenocarcinoma with distinct biology, immune profiles, and therapeutic vulnerabilities. Cancer Discov 5:860-877

24. Chen N, Fang W, Lin Z, Peng P, Wang J, Zhan J, Hong S, Huang J, Liu L, Sheng J, Zhou T, Chen Y, Zhang H, Zhang L (2017) KRAS mutation-induced upregulation of PD-L1 mediates immune escape in human lung adenocarcinoma. Cancer Immunol Immunother 66:1175-1187 